\title{
Internal Energy Distributions Deposited in Doubly and Singly Charged Tungsten Hexacarbonyl Ions Generated by Charge Stripping, Electron Impact, and Charge Exchange*
}

\author{
R. G. Cooks \\ Department of Chemistry, Purdue University, West Lafayette, Indiana, USA
}

T. Ast

Faculty of Technology and Metallurgy, Belgrade, Yugoslavia

B. Kralj, V. Kramer, and D. Žigon

Jozef Stefan Institute, Ljubljana, Yugoslavia

The distribution $P(\epsilon)$ of internal energies deposited in $\mathrm{W}(\mathrm{CO})_{6}{ }^{+\cdot}$ ions upon charge stripping (that is, electron detachment to yield the doubly charged ion in the course of a single kiloelectronvolt energy collision) was estimated by a thermochemical method from the measured relative abundances of the doubly charged fragment ions produced. The thermochemical information needed to estimate $P(\epsilon)$ was obtained by measuring the threshold translational energy losses associated with charge stripping of the singly charged fragment ions, $W(\mathrm{CO})_{n}^{+}$ ( $n=0-5$ ). The $P(\epsilon)$ curve falls exponentially with increasing internal energy. The average energy transferred to $\mathrm{W}(\mathrm{CO})_{6}{ }^{+}$upon a $7.8-\mathrm{keV}$ collision with $\mathrm{O}_{2}$ is $19 \mathrm{eV}$, yielding $\mathrm{W}(\mathrm{CO})_{6}{ }^{2+}$ ions with an average of $4 \mathrm{eV}$ of internal energy. In its general appearance, the $P(\epsilon)$ distribution associated with charge stripping is similar to the curves obtained from simple collisional activation of either $\mathrm{W}(\mathrm{CO})_{6}{ }^{+}$or $\mathrm{W}(\mathrm{CO})_{6}{ }^{2+}$ in kiloelectronvolt energy gaseous collisions. Given that charge stripping occurs by way of an electronic excitation process, this similarity in the energy deposition function is taken to indicate that electronic excitation is also the major mechanism for simple collisional activation in this system at zero scattering angle in the kiloelectronvolt energy regime. The internal energy distribution associated with a related charge-stripping process, charge inversion from the metal carbonyl anions to yield the corresponding cations, was also recorded. This reaction shows a large $(\sim 7 \mathrm{eV})$ average internal energy deposition with a distribution that indicates near-zero probability of formation of unexcited ions. These data are tentatively interpreted in terms of vibrational electron detachment. The internal energy distribution associated with an exothermic process, charge exchange $\left[\mathrm{W}(\mathrm{CO})_{6}{ }^{2+}+\mathrm{O}_{2} \rightarrow \mathrm{W}(\mathrm{CO})^{+}{ }_{6}+\mathrm{O}_{2}{ }^{+\cdot}\right]$, was also characterized. Unexpectedly strong coupling of translational to internal energy is observed, and there is a large probability of depositing internal energies in excess of $10 \mathrm{eV}$, even though the exothermicity is only $3 \mathrm{eV}$. Finally, the internal energy distributions associated with the formation of doubly charged $\mathrm{W}(\mathrm{CO})_{6}{ }^{2+}$ ions by electron ionization have been measured. Unlike the distribution for charge stripping, but like that for singly charged ions generated by electron impact, this distribution shows considerable structure, presumably due to Franck-Condon factors. (J Am Soc Mass Spectrom 1990, 1, 16-27)

$\mathrm{T}$ There is growing interest in inelastic collisions of polyatomic molecules in which translational energy is converted into internal energy [1]. Because the behavior of isolated molecules is controlled

Address reprint requests to R. G. Cooks, Department of Chemistry, Purdue University, West Lafayette, IN 47907 .

* A preliminary communication of this work appeared in Advances in Mass Spectrometry 1989, 11A, 1036. by the internal energy distribution $P(\epsilon)$ of the molecular population, it is of fundamental significance to be able to characterize this distribution. Several investigators have given this problem attention, particularly as it pertains to gas-phase ions encountered in mass spectrometry [2]. Furthermore, current interest in the chemistry of isolated doubly charged ions [3] makes it important to develop methods for character- 
izing their internal energy distributions. Our study is the first reported attempt to do so. It uses an approximate method [4] of estimating $P(\epsilon)$, one previously tested and used for singly charged molecular cations [5].

Doubly charged ions are frequently generated by charge stripping [6], that is, by electron detachment of positive ions in high-energy (kiloelectronvolt range) collisions,

$$
\mathrm{m}_{1}^{+}+\mathrm{N} \rightarrow \mathrm{m}_{1}^{2+}+\mathrm{N}+\mathrm{e}^{-}
$$

Charge stripping is normally highly endothermic; for a molecule with a typical ionization energy of 10 $\mathrm{eV}$ and a double ionization energy of $27 \mathrm{eV}$, the process is $17 \mathrm{eV}$ endothermic at threshold. One result is that it has been found to be useful in characterizing nonisomerized ions lying deep in potential wells when stable ions of higher internal energy, which are accessible by other methods of ion structural characterization, may have isomerized [7]. It is also well known that charge stripping can be accompanied by dissociation of the charge-stripped ion; this can result in either singly charged fragment ions (charge separation) or the formation of doubly charged fragment ions [8].

Charge stripping is useful in obtaining both thermochemical and structural information on doubly charged ions. The former information is derived from threshold measurements. These are not made by varying the projectile translational energy, as might be supposed, but rather by the more precise procedure of measuring the product translational energy distribution and deducing from this the minimum endoergicity $\left(Q_{\text {min }}\right)$ necessary to drive the highly endothermic reaction [9]. Structural information can be obtained by measuring the abundances of the fragment ions, both singly and doubly charged, derived by spontaneous or collision-activated dissociation (CAD) of the charge-stripped ions.

Another method of forming doubly charged polyatomic ions is by electron ionization (EI) of the neutral molecules,

$$
\mathrm{m}_{1}+\mathrm{e}^{-} \rightarrow \mathrm{m}_{1}^{2+}+3 \mathrm{e}^{-}
$$

There has been virtually no previous work on the internal energy distributions associated with this reaction, in contrast to a number of studies using a variety of methods that have been applied to EI leading to singly charged ions [2, 10]. Process (2) may also be associated with a high degree of internal excitation of the nascent doubly charged ion. The fact that doubly charged fragment ions are, common in the EI mass spectra of many slasses of compounds is consistent with their formation from internally excited doubly charged molecular ions. It is therefore of interest to have available a method capable of characterizing the internal energy distributions of doubly charged ions generated by both EI and charge stripping and to compare these distributions.

The method used here to approximate the inter- nal energy distribution of a population of ions has been described elsewhere [4]. It is based on simplifying assumptions about the kinetics of dissociation of ions that fragment by a linear sequence of reactions of known activation or, more correctly, critical energies and similar frequency factors. Briefly, the internal energy of each precursor ion determines how far it proceeds down a linear sequence of fragmentation reactions. The measured product ion distribution is transformed to an approximate internal energy distribution of the population of activated precursor ions by using the known thermochemistry of dissociation. The method has been tested [5] and appears to be particularly applicable to metal carbonyls, for which successive decarbonylations are the major fragmentation processes. A closely related method in which the fragment ion abundances are deconvoluted by using the known breakdown curve to yield the internal energy distribution [11] has also been successfully applied.

The choice of metal carbonyls for this study is also strongly recommended by the fact that these compounds undergo simple fragmentation reactions [12] and show fragmentation behavior for the singly charged positive and negative molecular ions analogous to that for the doubly charged molecular ions. This facilitates one of the objects of this study, which is to compare internal energy distributions of doubly and singly charged ions and obtain additional insights into the mechanisms of activation. The study therefore includes a limited inquiry into the collisional activation (CA) of the singly and doubly charged ions:

$$
\begin{aligned}
& \mathrm{m}_{1}^{+}+\mathrm{N} \rightarrow \mathrm{m}_{1}^{+*}+\mathrm{N} \\
& \mathrm{m}_{1}^{2+}+\mathrm{N} \rightarrow \mathrm{m}_{1}^{2+*}+\mathrm{N}
\end{aligned}
$$

In the former process, the metal carbonyl ions seem to be representative of other polyatomic ions in their $P(\epsilon)$ distributions [5]. The aims of this study have been pursued further by detcrmining internal energy distri butions associated with two related reactions, charge inversion of anions,

$$
\mathrm{m}_{1}^{-}+\mathrm{N} \rightarrow \mathrm{m}_{1}^{+*}+\mathrm{N}+2 \mathrm{e}^{-}
$$

and charge exchange of doubly charged ions,

$$
\mathrm{m}_{1}^{2+}+\mathrm{N} \rightarrow \mathrm{m}_{1}^{+*}+\mathrm{N}^{+}+2 \mathrm{e}^{-}
$$

Published data on simple CA of negative ions,

$$
\mathrm{m}_{1}^{-}+\mathrm{N} \rightarrow \mathrm{m}_{1}^{-*}+\mathrm{N}
$$

are also compared.

In characterizing the internal energy transferred to doubly charged ions when they are generated either by charge stripping or by EI, as well as in most of the other aspects of the present study, we chose to concentrate 
on the ion $\mathrm{W}(\mathrm{CO})_{6}^{2+}$. Several features recommend this particular selection:

1. The lowest mass fragment ion of $\mathrm{W}(\mathrm{CO})_{6}^{+\cdot}, \mathrm{W}^{+\cdot}$, is higher in mass-to-charge ratio than the product of charge stripping, $\mathrm{W}(\mathrm{CO})_{6}^{2+}$, and hence there is no overlap between the regions of the spectra containing singly and doubly charged ions.

2. Fragmentation occurs principally by a series of simple bond cleavages (successive decarbonylations), each step requiring an increasing activation energy.

3. Charge separation reactions are unlikely, the heavy metal preferring to carry both charges, and so branching of the fragmentation sequence into the singly charged manifold is avoided.

4. The internal energy deposition associated with simple $\mathrm{CAD}$ of $\mathrm{W}(\mathrm{CO})_{6}^{+\cdot}$ is known [13] and can therefore be compared with the results of dissociative charge stripping.

There is one difficulty in determining approximate internal energy distributions from the doubly charged metal carbonyls by the thermochemical method, and this is the fact that there are no published values for the activation energies for decarbonylation of doubly charged metal carbonyls. Nevertheless, threshold translational energy loss measurements on the charge-stripping process $\mathrm{W}(\mathrm{CO})_{n}{ }^{+} \rightarrow \mathrm{W}(\mathrm{CO})_{n}{ }^{2+}$ can be equaled, as is usual in high-energy, small-angle collisions [1a], to the minimum endothermicity of the reaction. Together with the known heats of formation of the singly charged ions, these data allow one to measure heats of formation of the corresponding doubly charged ions and to use this information for the estimation of the internal energy distribution associated with charge stripping.

\section{Experimental}

Experiments employed a triple-sector mass spectrometer of $\mathrm{EBE}$ geometry $(\mathrm{E}=$ electric sector, $\mathrm{B}=$ magnetic sector) that has been described elsewhere [14]. The first two analyzers were used to mass-select the ion of interest at unit mass resolution, and the final electric sector was used to analyze the products of collisions occurring in the third field-free region. For the precursor ions studied here, the peaks due to charge stripping and dissociative charge stripping of the selected singly charged ions occur in the region from $0.5 \mathrm{E}$ to zero (where $E$ is the electric sector voltage needed to transmit the main beam of stable ions), and those due to simple CAD occur between $0.5 E$ and $E$. Fragmentations of mass-selected doubly charged ions involving charge separation were sought by scanning the electric sector voltage over the range $E-2 E$, and dissociations to give doubly charged fragment ions were observed in the range $0-E$.

The ion accelerating voltage was $7.8 \mathrm{kV}$. Molecular oxygen was used as the target gas, and its pres-
Table 1. Electron impact mass spectra of $W(\mathrm{CO})_{6}$

\begin{tabular}{|c|c|c|c|c|c|}
\hline \multirow{3}{*}{$\begin{array}{l}\text { lon } \\
\text { composition } \\
W(\mathrm{CO})_{6}\end{array}$} & \multicolumn{3}{|c|}{ Singly charged ions } & \multirow{2}{*}{\multicolumn{2}{|c|}{$\begin{array}{c}\begin{array}{c}\text { Doubly } \\
\text { charged ions }\end{array} \\
70 \mathrm{eV}\end{array}$}} \\
\hline & \multirow{2}{*}{$\frac{70 \mathrm{eV}}{43}$} & \multirow{2}{*}{$\frac{25 \mathrm{eV}}{70}$} & \multirow{2}{*}{$\frac{15 \mathrm{eV}}{100}$} & & \\
\hline & & & & $4^{a}$ & $(15)^{b}$ \\
\hline$W(C O)_{6}$ & 5 & 15 & 37 & 1.9 & (7) \\
\hline $\mathrm{W}(\mathrm{CO})_{4} \mathrm{C}$ & 0.2 & 0.6 & - & 0.1 & 10.4) \\
\hline $\mathrm{W}(\mathrm{CO})_{4}$ & 44 & 60 & 63 & 7 & (26) \\
\hline $\mathrm{W}(\mathrm{CO})_{3} \mathrm{C}$ & 1 & 0.8 & - & 0.6 & $(2.2$ \\
\hline $\mathrm{W}(\mathrm{CO})_{3}$ & 100 & 100 & 54 & 18 & (67) \\
\hline $\mathrm{W}(\mathrm{CO})_{2} \mathrm{C}$ & 1 & 0.7 & - & 3.5 & (13) \\
\hline $\mathrm{W}\left(\mathrm{CO}_{2}\right.$ & 45 & 55 & 2.5 & 27 & $(100)$ \\
\hline wiCO)C & 8 & - & - & 11 & (41) \\
\hline $\mathrm{W}(\mathrm{CO})$ & 46 & 31 & - & 18 & (67) \\
\hline wc & 17 & - & - & 2.4 & (9) \\
\hline$w$ & 39 & 4 & - & 2.2 & (8) \\
\hline
\end{tabular}

a Relative to singly charged ions.

- Relative to most abundant doubly charged ion.

sure was adjusted so as to cause attenuation of the ion abundance due to the stable ion beam by $50 \%$ or by some other specified value. Ionization was by EI (70 $\mathrm{eV}$, unless otherwise specified). The ion source temperature was $100^{\circ} \mathrm{C}$. The $\mathrm{W}(\mathrm{CO})_{6}$ sample was introduced through a heated gallium reservoir introduction system. Ion currents achieved with this system were stable for several hours.

Minimum endothermicity $\left(Q_{\min }\right)$ values were measured by using slow scans ( 5 min per $1 \%$ change in $E$ ) across the charge-stripping peak. Linear extrapolation yielded onsets that were corrected by measuring the process $\mathrm{C}_{7} \mathrm{H}_{8}^{+\cdot} \rightarrow \mathrm{C}_{7} \mathrm{H}_{8}^{2+}$ in toluene $\left(Q_{\min }=15.7 \mathrm{eV}\right)$ [6]. Results are precise to $\pm 0.2 \mathrm{eV}$ and are estimated to be accurate to $\pm 0.3 \mathrm{eV}$.

\section{Results and Discussion}

\section{Features of the Spectra}

Electron ionization mass spectra of $\mathrm{W}(\mathrm{CO})_{6}$ were obtained by using $70 \mathrm{eV}, 25 \mathrm{eV}$, and $15 \mathrm{eV}$ electron energy, and the resulting ion abundances are listed in Table 1 . Note the presence of doubly charged ions, some of which exhibit considerable abundance. At $70 \mathrm{eV}$ and $25 \mathrm{eV}$, the EI mass spectra show $\mathrm{W}(\mathrm{CO})_{3}^{+\cdot}$ as the base peak; at $15 \mathrm{eV}$, the molecular ion takes its place. Note the very low abundance of $\mathrm{W}(\mathrm{CO})_{5}^{+*}$, which is reflected in a minimum in the internal energy distribution curve (see below). In agreement with their high activation energies, $\mathrm{WC}^{+\cdot}$ and $\mathrm{W}(\mathrm{CO}) \mathrm{C}^{+-}$are absent from the 25-eV spectrum whereas at $15 \mathrm{eV}$ no $\mathrm{W}(\mathrm{CO})_{m} \mathrm{C}^{+}$ions are observed.

Collision-activated dissociation product ion spectra of both $\mathrm{W}(\mathrm{CO})_{6}^{+\cdot}$ and $\mathrm{W}(\mathrm{CO})_{6}^{2+}$ were obtained at 7.8 $\mathrm{keV}$ ion energy and several pressures with $\mathrm{O}_{2}$ used as the collision gas (Table 2). In the absence of collision gas, only a small amount of $C O$ loss was observed from each precursor ion. Abundance data for $\mathrm{W}(\mathrm{CO})_{6}^{+\cdot}$ ions 
Table 2. Collision-activated dissociation spectra of $\mathrm{W}(\mathrm{CO})_{6}^{+\cdot}$ and $\mathrm{W}(\mathrm{CO})_{6}^{2+}$

\begin{tabular}{|c|c|c|c|}
\hline \multirow{2}{*}{$\begin{array}{l}\text { Ion } \\
\text { composition }\end{array}$} & \multicolumn{2}{|c|}{ CAD of $W(C O)_{6}^{+}$} & \multirow{2}{*}{$\frac{C A D \text { of } W(C O)_{6}^{2+}}{50 \%}$} \\
\hline & $50 \%$ & $10 \%$ & \\
\hline $\mathrm{W}(\mathrm{CO})_{5}$ & 100 & 100 & 100 \\
\hline $\mathrm{W}(\mathrm{CO})_{4} \mathrm{C}$ & 2 & 2.5 & - \\
\hline $\mathrm{W}(\mathrm{CO})_{4}$ & 37 & 26 & 35 \\
\hline $\mathrm{W}(\mathrm{CO})_{3} \mathrm{C}$ & 5 & 4 & 4 \\
\hline $\mathrm{W}(\mathrm{CO})_{3}$ & 37 & 28 & 38 \\
\hline $\mathrm{W}(\mathrm{CO})_{2} \mathrm{C}$ & 3 & 2.5 & 7 \\
\hline $\mathrm{W}(\mathrm{CO})_{2}$ & 20 & 14 & 30 \\
\hline W(co)c & 5 & 3.5 & 6 \\
\hline$W(C O)$ & 13 & 8 & 11 \\
\hline WC & 3 & 1 & 1.5 \\
\hline$w$ & 6 & 3.5 & 2.5 \\
\hline
\end{tabular}

The precursor ion abundance is not included.

- Bearn attenuation (\%) upon intraduction of molecular oxygen as collision gas.

are not considered because it is not possible to differentiate precursor ions that do not experience collisions from those that collide but are stable to dissociation. Note that lower mass ions have much lower relative abundances in the CAD spectra than in the 70-eV EI spectrum, pointing to the fact that higher internal energies are more probable in the latter experiment. Note that the usual discrimination effects against low-mass fragment ions are minimized by the choice of the carbonyl of the heavy metal tungsten as the precursor ion.

The CAD product ion spectrum of stable $\mathrm{W}(\mathrm{CO})_{6}^{2+}$ ions generated in the ion source was recorded by scanring the electric sector voltage from 0 to $E$; in this region, doubly charged fragment ions are observed, and their abundances are also listed in Table 2. To determine whether charge separation reactions take place, we also scanned the electric sector voltage from $E$ to $2 E$; we observed no charge separation processes, but peaks did appear due to charge exchange followed by fragmentation, a process that is discussed below. (The processes are distinguished by the large kinetic energy release, and hence the wide peaks, associated with charge separation [15].)

Dissociative charge stripping of $\mathrm{W}(\mathrm{CO})_{6}^{+-}$was carried out under the same conditions, and the results obtained are listed in Table 3. As with the other spectra, our interest is in the internal energy carried by the nascent activated ion. The results of this experiment show that significant amounts of internal energy are transferred to the ion. There is a high probability of transferring energy in excess of the minimum of 15 $\mathrm{eV}$ required to form unexcited $W(\mathrm{CO})_{6}^{2+}$ ions, and this is reflected in the abundance of the lower mass fragment dications, which require higher energy for their formation. The spectra obtained at different collision gas pressures $(50,10$, and $5 \%$ beam attenuation) show little variation; the significance of this observation is discussed further on.
Table 3. Dissociative charge-stripping spectra of $\mathrm{W}(\mathrm{CO})_{6}^{+}$

\begin{tabular}{lrrr}
\hline & \multicolumn{3}{c}{ Relative abundance } \\
\cline { 2 - 4 } Product & $50 \%$ & $10 \%$ & $5 \%$ \\
\hline ion & 58 & 50 & 47 \\
\hline$W(\mathrm{CO})_{6}^{2+}$ & 100 & 100 & 100 \\
$W(\mathrm{CO})_{5}^{2+}$ & 5 & 5 & 3 \\
$W(\mathrm{CO})_{4} \mathrm{C}^{2+}$ & 51 & 53 & 49 \\
$W(\mathrm{CO})_{4}^{2+}$ & 28 & 31 & 31 \\
$W(\mathrm{CO})_{3} \mathrm{C}^{2+}$ & 44 & 40 & 43 \\
$W(\mathrm{CO})_{3}^{2+}$ & 22 & 19 & 22 \\
$W(\mathrm{CO})_{2} \mathrm{C}^{2+}$ & 39 & 37 & 33 \\
$W(\mathrm{CO})_{2}^{2+}$ & 14 & 10 & 8 \\
$W(\mathrm{CO})^{2+}$ & 18 & 12 & 8 \\
$W^{2+}(\mathrm{CO})^{2+}$ & 2 & 2 & 1 \\
$W^{2+}$ & 2 & - & 2 \\
$W^{2+}$ & &
\end{tabular}

a Beam attenuation (\%) upon introduction of molecular oxygen as collision gas.

Table 4 shows spectra due to dissociative charge exchange of the doubly charged $\mathrm{W}(\mathrm{CO})_{6}^{2+}$ ions extracted from the ion source. Even at background gas pressures, the $\mathrm{W}(\mathrm{CO})_{6}^{2+}$ ions give both the intact singly charged $\mathrm{W}(\mathrm{CO})_{6}^{+}$ions and fragments due to further dissociation accompanied by $\mathrm{CO}$ losses. At these low pressures (ca. $1 \times 10^{-7}$ torr, indicated), CAD of both $\mathrm{W}(\mathrm{CO})_{6}^{2+}$ and $\mathrm{W}(\mathrm{CO})_{6}^{+-}$is negligible, indicating that the observed fragment ions are the result of the excess energy lodged in the charge-exchanged product upon formation; that is, the process occurring is dissociative charge exchange, eq 6 . The distribution of products changes only slightly when a target gas is added to attenuate the parent $\mathrm{W}(\mathrm{CO})_{6}^{2+}$ signal by $50 \%$. Hence, even at this pressure, dissociative charge exchange remains the major contributor to the observed spectrum.

Table 4. Dissociative charge-exchange spectra of $\mathrm{W}(\mathrm{CO})_{6}^{2+}$

\begin{tabular}{|c|c|c|}
\hline \multirow[b]{2}{*}{ Product ion } & \multicolumn{2}{|c|}{ Relative abundance } \\
\hline & $50 \%$ & $0 \%$ \\
\hline $\mathrm{W}(\mathrm{CO})_{6}^{+}$ & 61 & 53 \\
\hline $\mathrm{W}(\mathrm{CO})_{5}^{+}$ & 98 & 100 \\
\hline $\mathrm{W}(\mathrm{CO})_{4}^{+}$ & 76 & 59 \\
\hline $\mathrm{W}(\mathrm{CO})_{3} \mathrm{C}^{+}$ & 5 & 5 \\
\hline $\mathrm{W}(\mathrm{CO})_{3}^{+}$ & 100 & 70 \\
\hline $\mathrm{W}(\mathrm{CO})_{2} \mathrm{C}^{+}$ & 7 & 5 \\
\hline $\mathrm{W}(\mathrm{CO})_{1}^{+}$ & 73 & 50 \\
\hline Wicolc + & 21 & 14 \\
\hline $\mathrm{W}(\mathrm{CO})^{+}$ & 76 & 46 \\
\hline$w C^{+}$ & 36 & 18 \\
\hline$w^{+}$ & 88 & 52 \\
\hline
\end{tabular}

- Beam attenuation upon introduction of molecular oxygen collision gas.

- No molccular oxygen gas added; charge exchange occurred with residual gas in the instrument (indicated analyzer pressure $1 \times 10^{-7}$ torr). 
All five types of spectra (Tables 1-4) are dominated by fragment ions of the type $\mathrm{W}(\mathrm{CO})_{n}(n=0-5)$ that arise from successive decarbonylation reactions of the singly or doubly charged molecular ion. In addition, the presence of ions of the type $\mathrm{W}(\mathrm{CO})_{n} \mathrm{C}$ $(n=0-4)$ can be noted in all of the spectra. The fact that $\mathrm{W}(\mathrm{CO})_{4} \mathrm{C}^{+}$and $\mathrm{W}(\mathrm{CO})_{4} \mathrm{C}^{2+}$ are the highest mass ions of this kind observed suggests that they are formed from the molecular ion by loss of $\mathrm{CO}_{2}$. Lower mass ions in this series may then be formed by successive $\mathrm{CO}$ losses. Indeed, examination of the $\mathrm{CAD}$ spectra of $\mathrm{W}(\mathrm{CO})_{3} \mathrm{C}^{+}$and $\mathrm{W}(\mathrm{CO})_{2} \mathrm{C}^{+}$ions shows that they fragment exclusively by $\mathrm{CO}$ loss reactions; no $\mathrm{W}(\mathrm{CO})_{n}^{+}$ fragments are observed.

Decarbonylation and decarboxylation (followed by further decarbonylations) are thus competitive fragmentation pathways of the singly and doubly charged molecular ions of $\mathrm{W}(\mathrm{CO})_{6}$. The latter process, however, is of far less importance; moreover, because of the known [16], very high, appearance energies for $\mathrm{W}(\mathrm{CO}) \mathrm{C}^{+}(25.9 \mathrm{eV})$ and $\mathrm{WC}^{+}(28.8 \mathrm{eV}), \mathrm{W}(\mathrm{CO})_{n} \mathrm{C}$ type ions are expected to be high-energy fragments. For these reasons we feel justified in excluding the decarboxylation products from consideration when we construct approximate internal energy distributions. Later in the paper, this assumption is tested further.

\section{Origin of the Doubly Charged Fragment Ions in Dissociative Charge Stripping}

There are two routes through which doubly charged fragment ions $\left(\mathrm{F}^{2+}\right)$ might be formed in a chargestripping experiment:

$$
\begin{gathered}
\mathrm{W}(\mathrm{CO})_{6}^{+\cdot} \stackrel{\mathrm{O}_{2}}{\longrightarrow} \mathrm{W}(\mathrm{CO})_{6}^{2+*} \rightarrow F^{2+} \\
\mathrm{W}(\mathrm{CO})_{6}^{+} \stackrel{\mathrm{O}_{2}}{\longrightarrow} \mathrm{F}^{+\stackrel{\mathrm{O}_{2}}{\longrightarrow}} F^{2+}
\end{gathered}
$$

Sequence (8) can occur in a single collision, and it yields internally activated doubly charged ions, which may then dissociate spontaneously. Reaction sequence (9) requires at least two collisions: the first to cause dissociation and the second to strip an electron from the product ion.

To distinguish between these reaction sequences, measurements were made at collision gas pressures corresponding to 5,10 , and $50 \%$ attenuation of the intensity of the main beam of stable ions. As seen in Table 3 , the data show a remarkably small pressure dependence, which strongly suggests that a singlecollision process of low cross section is predominantly involved. Hence, the dissociative charge-stripping sequence (8) appears to be the dominant process. [Note that metastable ion dissociations of $\mathrm{W}(\mathrm{CO})_{6}^{+\cdot}$ could also contribute, via a single-collision process, to the observation of $\mathrm{W}(\mathrm{CO})_{n}^{2+}$ fragment ions. Metastable ion dissociations of $\mathrm{W}(\mathrm{CO})_{6}^{+\cdot}$, however, are limited to production of $\mathrm{W}(\mathrm{CO})_{5}^{+}$in abundances that are much lower than that observed for simple charge stripping of $\left.\mathrm{W}(\mathrm{CO})_{6}^{+\cdot} \cdot\right]$

Further information on the two alternative sequences can be obtained from data for the ions $\mathrm{W}(\mathrm{CO})_{3} \mathrm{C}^{+}$and $\mathrm{W}(\mathrm{CO})_{2} \mathrm{C}^{+}$. The $\mathrm{CAD}$ product ion spectrum ( $50 \%$ attenuation) of the molecular ion $\mathrm{W}\left(\mathrm{CO}_{6}^{+\cdot}\right.$ (Table 2) shows that these two ions are formed in relative abundances of $5 \%$ and $3 \%$, respectively. On the other hand, dissociative charge stripping of the molecular ion under the same conditions (Table 3) shows the corresponding $\mathrm{W}(\mathrm{CO})_{3} \mathrm{C}^{2+}$ and $\mathrm{W}\left(\mathrm{CO}_{2}\right) \mathrm{C}^{2+}$ ions with abundances of $28 \%$ and $22 \%$, respectively. If sequence (9) were occurring, these results would require that both of these ions have a very large cross section for charge stripping (the second step) to cause this great increase in their relative abundances compared to their abundances in the simple product ion spectra [the first step of sequence (9)]. Independent measurements on $\mathrm{W}(\mathrm{CO})_{3} \mathrm{C}^{+}$and $\mathrm{W}\left(\mathrm{CO}_{2}\right) \mathrm{C}^{+}$formed in the source, however, show that, quite to the contrary, these ions do not undergo charge stripping to any measurable extent, which strongly supports sequence (8). In this context, it is interesting to note that $W(\mathrm{CO})_{3} \mathrm{C}^{2+}$ and $\mathrm{W}(\mathrm{CO})_{2} \mathrm{C}^{2+}$ are also present in the 70-eV mass spectrum and in the C.AD spectrum of $\mathrm{W}(\mathrm{CO})_{6}^{2+}$. All of these observations point to the fact that these ions are formed by fragmentation reactions from doubly charged precursors and not by charge stripping of the singly charged fragment ions.

The reasons just given justify treating the data in terms of the reaction sequence in which charge stripping is followed by dissociation. The possibility of a small contribution from the dissociation/chargestripping sequence cannot be excluded, although the near identity of the low- and high-pressure data suggests either that just one reaction occurs or that the two processes give very similar product distributions. As will be apparent after the data have been analyzed, the internal energy distributions for CAD of singly charged ions and for dissociative charge stripping are indeed rather similar. Hence, even if there is a small contribution from the dissociation/stripping sequence, the resulting product distribution will indicate the approximate form of the internal energy distribution of the doubly charged ions generated upon charge stripping.

\section{Thermochemical Data}

The data of Tables 1-4 can be used to estimate internal energy distributions in activated $\mathrm{W}(\mathrm{CO})_{6}^{+}$and $W(\mathrm{CO})_{6}^{2+}$ ions. To make these cstimates one needs to know the activation (critical) energies for fragment ion formation. For the singly charged fragment ions, this information is readily available from published data for their appearance energies [16]. To obtain the activation energies for doubly charged ions, the minimum endothernicity $\left(Q_{\min }\right)$ of the reaction was determined for each of the fragment ions. This value was obtained from charge stripping by measuring the translation en- 
ergy loss in the process $[6,9]$. If we define $Q_{\min }(n)$ as

$$
\mathrm{W}(\mathrm{CO})_{n}^{+} \rightarrow \mathrm{W}(\mathrm{CO})_{n}^{2+} \quad \Delta H_{\text {reaction }} \equiv Q_{\min }(n)
$$

the activation (critical) energy $E_{0}^{2+}$ for the reaction $\mathrm{W}(\mathrm{CO})_{6}^{2+} \rightarrow \mathrm{W}(\mathrm{CO})_{n}^{2+}+(6-n) \mathrm{CO}$ is given by

$$
\begin{aligned}
E_{0}^{2+}= & \Delta H_{\mathrm{f}}\left(\mathrm{W}(\mathrm{CO})_{n}^{2+}\right)+(6-n) \Delta H_{\mathrm{f}}(\mathrm{CO}) \\
& -\Delta H_{\mathrm{f}}\left(\mathrm{W}(\mathrm{CO})_{6}^{2+}\right)
\end{aligned}
$$

But from eq 10,

hence

$$
\Delta H_{\mathrm{f}}\left(\mathrm{W}(\mathrm{CO})_{n}^{2+}\right)=\Delta H_{\mathrm{f}}\left(\mathrm{W}(\mathrm{CO})_{n}^{+}\right)+Q_{\min }(n)
$$

$$
\begin{aligned}
E_{0}^{2+}= & \Delta H_{\mathrm{f}}\left(\mathrm{W}(\mathrm{CO})_{n}^{+}\right)-\Delta H_{\mathrm{f}}\left(\mathrm{W}(\mathrm{CO})_{n}^{2+}\right) \\
& +(6-n) \Delta H_{\mathrm{f}}(\mathrm{CO})+Q_{\min }(n)
\end{aligned}
$$

If the difference in $Q_{\min }$ values when $n=n$ and $n=$ 6 is designuated $\Delta Q_{\min }$ and the activation energy for the corresponding singly charged ion fragmentation is designated as $E_{0}^{+}$, then

$$
\begin{aligned}
E_{0}^{2+}= & \Delta H_{f}\left(\mathrm{~W}\left(\mathrm{CO}_{n}^{+}\right)-\Delta H_{\mathrm{f}}\left(\mathrm{W}(\mathrm{CO})_{6}^{+}\right)\right. \\
& +\Delta Q_{\min }+(6-n) \Delta H_{\mathrm{f}}(\mathrm{CO}) \\
= & E_{0}^{+}+\Delta Q_{\min }
\end{aligned}
$$

Equation 15 represents the operation of a simple thermochemical cycle:

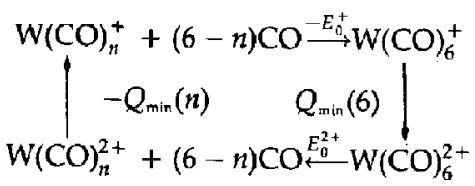

and it is used to calculate activation energies for dissociation of the doubly charged ions. The pertinent thermochemical data for both the singly and doubly charged ions are listed in Table 5 . Note that because threshold values are measured, we do not consider significant the possible effects $[9 \mathrm{e}, 17]$ of the nature of the target or of the pressure on the kinetic energy loss.

\section{Internal Energy Distributions}

Figure 1 displays the internal energy distribution for doubly charged $\mathrm{W}(\mathrm{CO})_{6}^{2+}$ ions generated by charge stripping of the corresponding long-lived singly charged ions. (The singly charged $W(C O)_{6}^{+-}$ions examined in this experiment have lifetimes of $26 \mu \mathrm{s}$

\begin{tabular}{|c|c|c|c|c|}
\hline & \multicolumn{2}{|c|}{$\begin{array}{c}\text { Singly } \\
\text { charged ions }\end{array}$} & \multicolumn{2}{|c|}{$\begin{array}{c}\text { Doubly } \\
\text { charged ions }\end{array}$} \\
\hline & $\mathrm{IE} / \mathrm{AE}$ & $E_{0}^{*}$ & $Q_{\min }{ }^{b}$ & $E_{0}^{2+c}$ \\
\hline$W\left(\mathrm{CO}_{\mathrm{B}}\right.$ & 8.5 & 0 & 15.0 & 0 \\
\hline $\mathrm{W}(\mathrm{CO})_{5}$ & 9.7 & 1.2 & 14.8 & 1.0 \\
\hline $\mathrm{W}(\mathrm{CO})_{4}$ & 11.9 & 3.4 & 15.4 & 3.8 \\
\hline $\mathrm{W}(\mathrm{CO})_{3}$ & 13.7 & 5.2 & 16.0 & 6.2 \\
\hline$w(\mathrm{CO})_{2}$ & 16.0 & 7.5 & 16.0 & 8.5 \\
\hline$W(C O)$ & 18.6 & 10.1 & 17.1 & 12.2 \\
\hline$w$ & 21.5 & 13.0 & 17.1 & 15.1 \\
\hline$w C$ & 28.8 & 20.3 & 17.8 & 23.1 \\
\hline
\end{tabular}
before collision; they can therefore be assumed to be essentially unexcited because the activation energy for their lowest energy fragmentation, loss of $\mathrm{CO}$, is only $1.2 \mathrm{eV}$ [Table 5]. This would not be the case if long-lived excited states were represented, as they are for transition metal ions, some of their simpler compounds, and some clusters [18]). The data
Table 5. Thermochemical data for tungsten carbonyl ions $(\mathrm{eV})$

Average values of ionization or appearance energy (IE/AE) from ref. 16.

- Measured in this study, estimated uncertainty $\pm 0.3 \mathrm{eV}$.

- Calculated from eq $\mathbf{1 5 .}$

points in Figure 1 represent abundances of the observed $\mathrm{W}(\mathrm{CO})_{n}^{2+}(n=0-5)$ fragment ions, normalized for the internal energy interval over which they occur and plotted against the midpoint of this interval as abscissa. The result is a smooth curve in which internal energy falls exponentially. In this and all subsequent calculations, peak heights rather than areas were employed, although calculations leading to Figure 1 were repeated with peak areas. The distribution still falls exponentially, but higher energies are given somewhat greater weights. Similar but smaller effects occur in the CAD and dissociative charge-exchange spectra; in all cases the peaks due to multiple $\mathrm{CO}$ losses are broader because of the larger kinetic energy releases associated with these processes. To test further the assumption that only the predominant decarbonylation reaction sequence needs to be considered for constructing $P(\epsilon)$ distributions, the energies of the decarboxylation reaction products have been estimated by using known heats of formation of $\mathrm{W}^{2+}$ and $\mathrm{WC}^{2+}$ (from $Q_{\min }$ measurements, Table 5) and assuming that successive decarbonylations of $\mathrm{WC}(\mathrm{CO})_{n}^{2+}$ have the same energy requirement as those in the $\mathrm{W}(\mathrm{CO})_{n}^{2+}$ series. The estimated activation energies-W(CO) ${ }_{4} \mathrm{C}^{2+}$

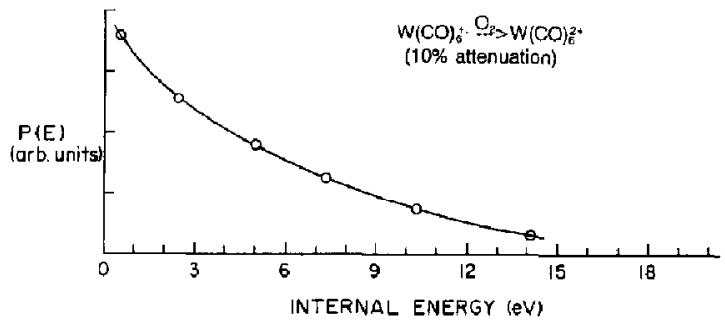

Figure 1. Internal energy distribution in doubly charged $\mathrm{W}(\mathrm{CO})_{6}^{2+}$ ions generated by charge stripping of $\mathrm{W}(\mathrm{CO})_{6}^{+}$in $7.8-\mathrm{keV}$ collisions with molecular oxygen. Target pressure corresponds to $10 \%$ attenuation of the $W^{(}(\mathrm{CO})_{6}^{+\cdot}$ beam. 


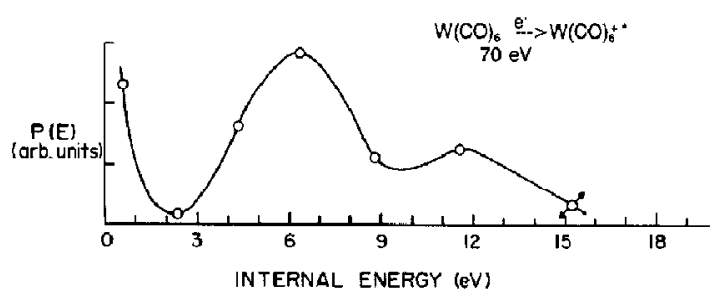

A.

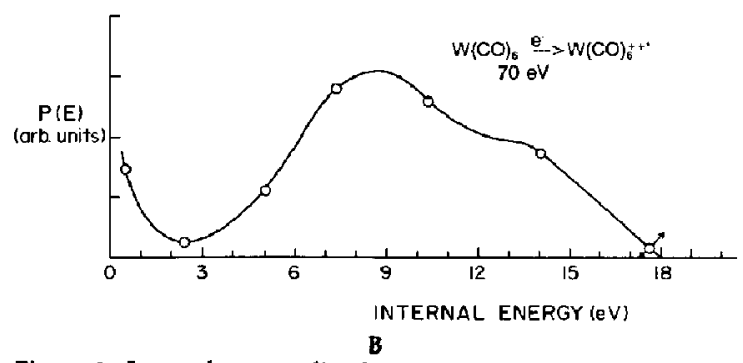

Figure 2. Internal energy distributions in (a) singly charged and (b) doubly charged molecular ions of $W(\mathrm{CO})_{6}$ generated by $70-\mathrm{eV}$ electron ionization.

$12.6 \mathrm{eV} ; \mathrm{W}(\mathrm{CO})_{3} \mathrm{C}^{2+}, 15.0 \mathrm{eV} ; \mathrm{W}(\mathrm{CO})_{2} \mathrm{C}^{2+}, 17.6 \mathrm{eV}$; $\mathrm{W}(\mathrm{CO}) \mathrm{C}^{2+}, 20.4 \mathrm{eV}$-and the measured value for $\mathrm{WC}^{2+}, 23.1 \mathrm{eV}$, allow us to plot the $P(\epsilon)$ curve to considerably higher internal energies. There is little change in the shape of the distribution when this series of ions is included. A similar procedure was applied in the singly charged ion series, again with no substantial change in the $P(\epsilon)$ distribution.

The distributions recorded at two other pressures, corresponding to $5 \%$ and $50 \%$ beam attenuation (see supplementary material) are very similar to the data shown in Figure 1, although the 50\% attenuation data show a small maximum at $6 \mathrm{eV}$ that could be due to a contribution from the dissociation/stripping sequence (eq 9) at these elevated collision gas pressures. From Figure 1 it is clear that the average internal energy deposited during charge stripping is $\sim 4 \mathrm{eV}$, making the overall stripping reaction with $\mathrm{O}_{2}$ endothermic by 19 $\mathrm{eV}\left(\mathrm{IP}^{\mathrm{II}}-\mathbb{P}^{\mathrm{I}}=Q_{\min }=15 \mathrm{eV}\right.$, Table 5).

Figure 2 compares the internal energy distributions for singly and doubly charged molecular ions of $\mathrm{W}(\mathrm{CO})_{6}$ generated by $70-\mathrm{eV}$ EI. These curves are remarkably different from those for charge stripping in that they show strong maxima and minima. The structure represented in both curves is typical of that observed previously in the internal energy distributions for various ions generated by EI [4]. It is probable that this structure, like that observed in the photoelectron spectra of metal carbonyls [19], is due to FranckCondon factors. It is worth noting that $W(\mathrm{CO})_{6}^{+\cdot}$ and $\mathrm{W}(\mathrm{CO})_{6}^{2+}$ both show $P(\epsilon)$ curves with a pronounced minimum at about $2 \mathrm{eV}$ and display maxima at $\sim 6 \mathrm{eV}$ and $9 \mathrm{eV}$, respectively. The doubly charged ions acquire somewhat greater internal energies than do their singly charged counterparts. As the ionizing electron energy is reduced, the $P(\epsilon)$ distributions change as ex-

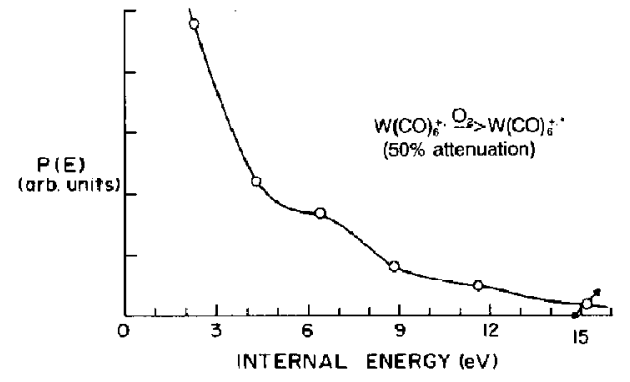

A

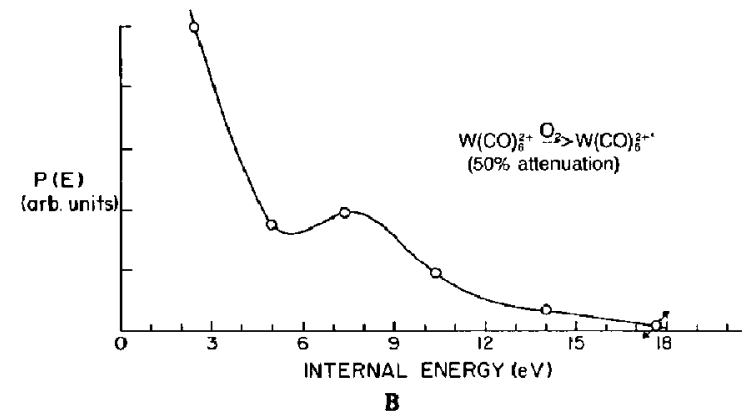

Figure 3. Internal energy distributions in (a) $\mathrm{W}(\mathrm{CO})_{6}^{+}$and (b) $\mathrm{W}(\mathrm{CO})_{6}^{2+}$ upon activation by collision with molecular oxygen at $7.8 \mathrm{keV}$ energy. Target pressure corresponds to $50 \%$ attenuation of the incident beam.

pected, with the high-energy region being truncated but the low-energy structure being retained (see supplementary material).

Figure 3 compares the internal energy distributions for $\mathrm{W}(\mathrm{CO})_{6}^{+\cdot}$ and $\mathrm{W}(\mathrm{CO})_{6}^{2+}$ activated by kiloelectronvolt collisions. The curves are similar in overall shape to many curves previously recorded for singly charged ions activated by collisions in the kiloelectronvolt energy range $[4,5]$. Note that the good agreement between the present $7.8 \mathrm{-keV}$ data and data for singly charged metal carbonyl ions recorded earlier with a different target gas and an instrument of different geometry [13] indicates that discrimination effects are not very large in this study. The local maximum at $\sim 6 \mathrm{eV}$ observed at $50 \%$ attenuation in the $P(\epsilon)$ distribution for singly charged ions is reproduced in the corresponding $10 \%$ attenuation data but is not observed in the distribution for the lower analogue, $\mathrm{W}(\mathrm{CO})_{5}^{+\cdot}$ (see supplementary material). The doubly charged ion again behaves similarly to its singly charged counterpart, although the local maximum occurs at $8 \mathrm{eV}$ and is more pronounced, consistent with the trend toward greater energy deposition in the doubly charged than in the singly charged ions.

The overall appearance of the internal energy distributions associated with CAD of both the singly and doubly charged ions is similar to that associated with charge stripping and rather different from those associated with EI. The much longer ion-target interaction times will reduce the importance of vertical electronic excitation controlled by Franck-Condon factors in CAD 
and charge stripping compared to EI. Note that the origin of the small peak seen in the $P(\epsilon)$ curves for CA is not known. It could be due to residual contributions from electronic excitation, but it could also be due to a contribution from direct vibrational excitation accompanying the electronic excitation process [20].

There are a number of reasons, although none are completely persuasive, to believe that charge stripping is an electronic excitation process. These include the fact that it is not observed at nonzero scattering angles [21] and the ease with which it is accomplished for atomic ions under conditions identical to those used here [22]. The similarities in the $\mathrm{CA}$ and chargestripping curves therefore argue for electronic excitation in kiloelectronvolt $\mathrm{CA}$. The general form of both sets of $P(\epsilon)$ curves (long tails to high internal energy) is consistent with expectations for electronic excitation [1a, 23].

A recent study [13] on the internal energy distributions deposited in negative metal carbonyl ions $\left[\mathrm{Cr}(\mathrm{CO})_{5}^{-}\right.$and $\left.\mathrm{Fe}(\mathrm{CO})_{4}^{-}\right]$upon $\mathrm{CAD}$ in kiloelectronvolt energy collisions shows $P(\epsilon)$ curves that fall off rapidly with increasing internal cncrgy. The curves are similar to those for the corresponding cations although they are truncated at internal energies greater than $6 \mathrm{eV}$, probably by the onset of electron detachment. Charge inversion [24] of $\mathrm{Fe}(\mathrm{CO})_{4}^{-}$and $\mathrm{Cr}(\mathrm{CO})_{5}^{-}$anions to give the corresponding cations,

$$
\mathrm{m}_{1}^{-}+\mathrm{N} \rightarrow \mathrm{m}_{1}^{+}+\mathrm{N}+2 \mathrm{e}^{-}
$$

was explored in the same study [13]. Energy transfer accompanying this charge-stripping reaction is of interest for comparison with the data for reaction (1). The data are reported in Table 6. Internal energy distributions for the nascent cations were not presented in ref 13 , but they have now been calculated, and the one for $\mathrm{Fe}(\mathrm{CO})_{4}^{-}$is presented in Figure 4 . A noteworthy feature of this curve is that the most probable internal energy of the singly charged ions generated by charge inversion is about $5 \mathrm{eV}$. However, the reaction is endothermic by $\sim 5.6 \mathrm{eV}$, that is, the ionization energy of $\mathrm{Fe}(\mathrm{CO})_{4}$ is estimated as $8 \mathrm{eV}$, and its electron affinity is $2.4 \mathrm{eV}$ [25]. In spite of this, the threshold process $(\epsilon=0)$ has zero probability. Anion charge inversion therefore gives internal energy distributions that are strikingly different from those for charge stripping of positive ions (eq 1), while also differing in a pronounced fashion from those for EI and for low-energy CAD. This result is surprising because the reaction (eq 17) represents a charge-stripping reaction, although the endothermicity is smaller than that required to strip singly charged ions to form doubly charged cations (eq 1). It is noteworthy that CAD of the same anions [13] reveals that ions with internal energies of $5 \mathrm{eV}$ are stable on the time scale of the experiment [13]. Because the electron affinity of $\mathrm{Fe}(\mathrm{CO})_{4}$ is only $2.4 \mathrm{eV}$ [25], these long-lived ions must be thermodynamically unstable. Hence electron detachment
Table 6. Dissociative charge-inversion spectra of $\mathrm{Fe}(\mathrm{CO})_{4}^{-}$and $\mathrm{Cr}(\mathrm{CO})_{5}^{-}$

\begin{tabular}{|c|c|}
\hline Product ion & Relative abundance \\
\hline $\mathrm{Fe}(\mathrm{CO})_{4}^{+}$ & 0 \\
\hline $\mathrm{Fe}(\mathrm{CO})_{3} \mathrm{C}^{+}$ & 0 \\
\hline $\mathrm{Fe}(\mathrm{CO})_{3}^{+}$ & 1 \\
\hline $\mathrm{Fe}\left(\mathrm{CO}_{2}\right)_{2} \mathrm{C}^{+}$ & 7 \\
\hline $\mathrm{Fe}(\mathrm{CO})_{2}^{+}$ & 72 \\
\hline $\mathrm{Fe}(\mathrm{CO}) \mathrm{C}^{+}$ & 10 \\
\hline $\mathrm{Fe}(\mathrm{CO})^{+}$ & 100 \\
\hline $\mathrm{FeC}^{+}$ & 15 \\
\hline $\mathrm{Fe}^{+}$ & 94 \\
\hline \multicolumn{2}{|c|}{$\mathrm{Cr}(\mathrm{CO})_{5}^{-}$} \\
\hline $\mathrm{Cr}(\mathrm{CO})_{5}^{+}$ & 0 \\
\hline $\operatorname{Cr}\left(\mathrm{CO}_{4}\right)^{+}$ & 1 \\
\hline $\mathrm{Cr}\left\langle\mathrm{CO}_{3} \mathrm{C}^{+}\right.$ & 2 \\
\hline $\mathrm{Cr}(\mathrm{CO})_{3}^{+}$ & 9 \\
\hline $\mathrm{Cr}\left(\mathrm{CO}_{2} \mathrm{C}^{+}\right.$ & 4 \\
\hline $\mathrm{Cr}(\mathrm{CO})_{2}^{+}$ & 60 \\
\hline $\mathrm{Cr}(\mathrm{CO}) \mathrm{C}^{+}$ & 20 \\
\hline $\mathrm{Cr}(\mathrm{CO})^{+}$ & 69 \\
\hline $\mathrm{CrC}^{+}$ & 8 \\
\hline $\mathrm{Cr}^{+}$ & 100 \\
\hline
\end{tabular}

(the first step of the charge-inversion process) is kinetically controlled and is complete only at internal energies roughly twice as great as the electron affinity. Extra internal energy above the thermochemical threshold is necessary for electron detachment from the anion but not from the cation. This result suggests that the electron detachment may occur by a vibrational excitation mechanism, a result for which there is precedent [26], and be subject to a kinetic shift. Although the internal energy distribution for charge inversion of anions is not well understood, it is of interest that distributions similar to those shown in Figure 4 were reported [27] for acetone-neutral molecules undergoing charge stripping,

$$
\mathrm{m}_{1}+\mathrm{N} \rightarrow \mathrm{m}_{1}^{+}+\mathrm{N}+\mathrm{e}^{-}
$$

Most probable energies of 5-10 eV were observed for various targets. Again, these data contrast strongly with the distribution of internal energies associated with the charge-stripping reaction, eq 1 .

In both $C A$ and the charge stripping of positive ions, the internal energy deposition appears to be dominated by the Massey adiabatic criterion [28], that the cross section $(\sigma)$ for transfer of internal energy $(Q)$ falls as $Q$ increases, following the equation

$$
\sigma=c e^{-\mathcal{Q} k}
$$

The data in both Figure 1 and Figure 3 can be fitted by this equation. Note also that the fact that the energy 


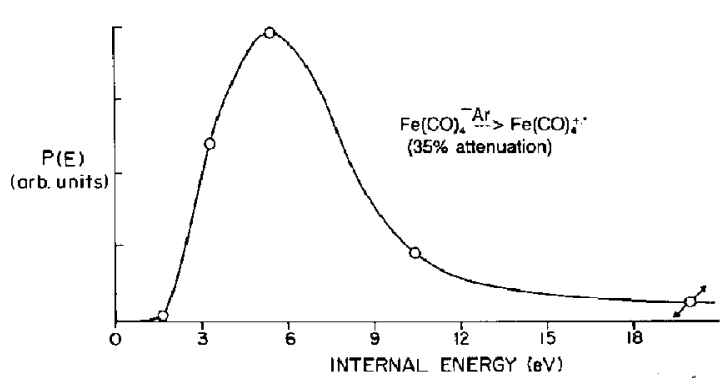

A

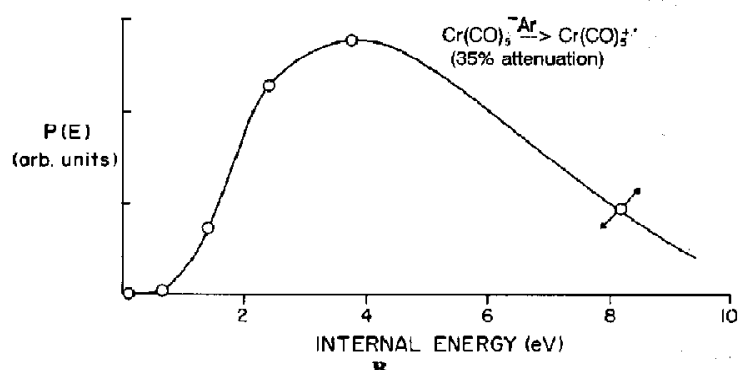

B

Figure 4. Internal energy distribution in (a) $\mathrm{Fe}(\mathrm{CO})_{4}^{+}$ions generated from $\mathrm{Fe}\left(\mathrm{CO}_{4}\right)^{-}$ions and (b) $\mathrm{Cr}(\mathrm{CO})_{5}^{+}$ions generated from $\mathrm{Cr}(\mathrm{CO})_{5}^{-}$ions by charge stripping at $7.0 \mathrm{keV}$. Target (Ar) pressure corresponds to $35 \%$ attenuation of the main beam intensity.

deposition in charge stripping (eq 1) is purely exponential is consistent with the large number of states at high energies and the resulting effective absence of effects of selection rules. The fact that charge stripping of anions (eq 17) does not obey the resonance criterion reinforces the suggestion that it may not occur by an electronic excitation mechanism.

It was of great interest, given these observations on internal energy distributions for metal carbonyls undergoing charge permutation collisions, to examine an exothermic charge-changing reaction for one of these systems. The chosen reaction,

$$
\mathrm{W}(\mathrm{CO})_{6}^{2+}+\mathrm{O}_{2} \rightarrow \mathrm{W}(\mathrm{CO})_{6}^{+\cdot *}+\mathrm{O}_{2}^{+}
$$

is exothermic by $2.9 \mathrm{eV}\left[Q_{\min }-\mathrm{IE}\left(\mathrm{O}_{2}\right)\right]$, and the translationally thermoneutral process is therefore predicted to yield predominantly $\mathrm{W}(\mathrm{CO})_{5}^{+\cdot}$ (Table 5). The results for dissociative charge exchange of $\mathrm{W}(\mathrm{CO})_{6}^{2+}$ are presented in Table 4, and the calculated internal energy distribution of the nascent product, $\mathrm{W}(\mathrm{CO})_{6}^{+}$, is given in Figure 5. The results show that far larger endothermicities than those predicted are very probable. Moreover, the process in which all the exothermicity $(2.9$ $\mathrm{eV}$ ) appears as internal energy of the $\mathrm{W}(\mathrm{CO})_{6}^{+\cdot}$ product is only slightly more probable than collisions (hatched area) in which the ion internal energy is smaller than the reaction exothermicity. This hatched area may represent (1) collisions leading to excited projectiles that undergo deactivation by photon emission [29] or (2) target excitation, which is unexpected given the large

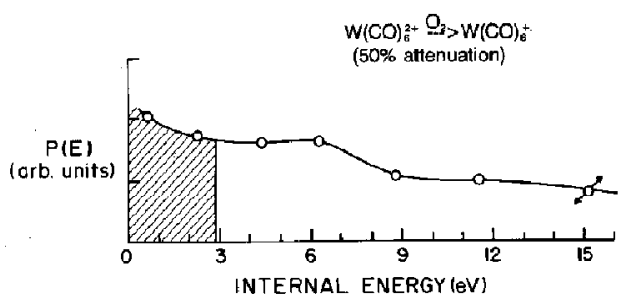

Figure 5. Internal energy distribution of $\mathrm{W}(\mathrm{CO})_{6}^{+\cdot}$ ions generated by charge exchange of $\mathrm{W}(\mathrm{CO})_{6}^{2+}$ with molecular oxygen target; $50 \%$ attenuation. The hatched areas of the distribution correspond to processes in which the internal energy of the $\mathrm{W}(\mathrm{CO})_{6}{ }^{+}$products is smaller than the exothermicity of the reaction.

number of degrees of freedom in the projectile and the single internal mode in $\mathrm{O}_{2}^{+}$, or (3) it may correspond to superelastic collisions [30] in which the projectile acquires extra translational energy from internal modes. The corresponding internal energy distribution for charge exchange of $\mathrm{W}(\mathrm{CO})_{3}^{2+}$ (see supplementary material) also shows both inelastic and apparently superelastic processes. Both results are consistent with recent observations of Boyd [31], who found that charge exchange of $\mathrm{CO}^{2+}$ occurs readily with all the rare gas targets, that is, with targets for which the reaction is exothermic, as well as with helium, even though the reaction with this particular target is $13 \mathrm{eV}$ endothermic at threshold. Inelastic collisions where the product ions are very highly excited are also very likely, as can be seen in the data given in Figure 5. Similarly, Vékey et al. [32] showed qualitatively that charge exchange of a varicty of doubly charged ions is accompanied by the transfer of considerable amounts of internal energy. Most significantly, rare gas targets of increasing ionization energy result in increasing energy deposition in charge exchange with doubly charged benzene [11] and pyridine [33], although the opposite might have been expected. Clearly, much remains to be learned regarding energy transfer in charge-exchange processes.

There is a large body of information available on charge-exchange reactions of molecular ions at low collision energies, where product excitation is bounded by the reaction exothermicity [34]. In addition, charge exchange in atomic systems at high energy has been much studied [35-37]. In this collision region, the probability of charge exchange is governed by the LandauZener-Stucckleberg approximation [36]. Nonresonant processes have maximum cross sections at nonzero kinetic energies, and this can result in more endothermic reactions having larger cross sections than less endothermic reactions at a particular collision energy. For polyatomic systems, resonant charge exchange can often be achieved provided one of the products is generated with internal excitation. It might be expected that simple resonant electron transfer would then prevail, provided observations were made at near-zero scattering angle. There is little experimental information on this point, even though charge exchange of polyatomic 
doubly charged ions has received considerable attention $[3,38]$, but at least some of the results $[11,23]$, including those given above, are inconsistent with this view.

\section{Conclusion}

Although the results given here emphasize a single system, they may be representative of the behavior of other polyatomic ions undergoing charge stripping and other charge-changing collisions. The internal energy distributions acquired by metal carbonyl ions upon CA were previously shown to be representative of those for organic ions [5]. Hence the principal result of this study, that charge stripping of singly charged ions to yield doubly charged ions is associated with an internal energy distribution that is characteristic of electronic excitation, is very satisfying. The results on doubly charged ions generated by EI also accord with expectation. On the other hand, the internal energy distributions associated with charge inversion (eq 5) and charge exchange (eq 6) have surprising features and will be the subject of further study.

It is important to note that there is by no means universal agreement on the operation of electronic excitation in CAD in the kiloelectronvolt range. Russell and co-workers, in particular, have argued that vibrational excitation is responsible $[9 \mathrm{e}, 17,39]$. We discuss this issue elsewhere and provide evidence for the operation of both activation mechanisms, the latter increasing rapidly in importance as the scattering angle is increased from $0^{\circ}[40]$. Russell and co-workers also argue that charge exchange has a much higher cross section than CA [9e, 39]; it would seem likely, therefore, that a reciprocal charge exchange would be a very probable means of performing CA by a purely electronic process. The large numbers of states of polyatomic ions would certainly allow nonequivalence in the two energy transfers and hence net activation.

The accuracy of the method used here to estimate the internal energy distributions of activated ion curves was previously discussed at some length for CAD [4, 5], and similar considerations apply to the chargechanging reactions detailed here. The method has relatively low resolution and should be used only to follow trends. Instrumental discrimination will also affect the results, although most such effects are massdependent and the relatively small range of masses covered when tungsten carbonyls are used minimizes these effects. Another approximation made is that ion abundances can be measured from peak heights, although kinetic energy releases vary, increasing with more extensive decarbonylation. The effects of this factor have been considered above. The method used here to characterize internal energy distributions also requires that the activated ion not be removed by internal energy-dependent processes other than the dissociations used to characterize $P(\epsilon)$. Electron detachment of activated negative ions to give unobservable neutral fragments is such a process, the effects of which on the internal energy distribution have been noted [13]. Charge-separation reactions of the fragment ions would also distort the estimated $P(\epsilon)$ curves because the resulting singly charged ions cannot be used in reconstructing the distributions. The lack of observable charge-separation reactions strengthens our confidence in the applicability of the methodology.

The $P(\epsilon)$ distributions estimated for singly and doubly charged ions can be compared with some confidence because the approximations made in arriving at these curves occur in both sets of data. It is therefore noteworthy that the two different methods of generating doubly charged ions ( $E I$ and charge stripping) both yield ions with internal energies that are substantially higher than those of the corresponding singly charged ions generated by the same methods. The fact that the high-energy regions of the distributions are enhanced is encouraging for applications that call for the study of highly excited ions.

Comparison of $P(\epsilon)$ curves for doubly charged ions activated in the three different ways-CAD, EI, and charge stripping-also benefits from the fact that approximations in the method tend to cancel. The main result of the comparison of the internal energy transfer due to charge stripping with that which occurs upon simple CA of the doubly charged ions is that the internal energy distributions are similar. The most significant difference between $C A D$ and stripping is the somewhat greater probability of transferring high internal energies in charge stripping. (This, of course, is in addition to the high threshold energy, $\sim 15 \mathrm{eV}$, required to form unexcited doubly charged molecular ions by charge stripping.) This is explained by the larger threshold energy that must be transferred to allow charge stripping compared with $\mathrm{CA}$. In a result that contrasts with both these experiments, the internal energy distribution $P(\epsilon)$ associated with $70-\mathrm{eV}$ electron ionization of $\mathrm{W}(\mathrm{CO})_{6}$ to produce doubly charged ions is different in shape and is highly structured. This is probably due to a Franck-Condon gap in excitation probability, which is also evident in the photoelectron spectrum [13], an observation that itself provides additional evidence that electronic excitation is a dominant mechanism in zero-angle kiloelectronvolt collisions of small polyatomic ions.

The results presented here on the internal energy deposition in polyatomic ions associated with charge exchange are among the first of their kind and should be useful because interest in using dissociative electric capture processes to characterize isomeric ion structures is growing [41]. Much more needs to be learned about this process, but the ease of translational to vibrational energy transfer associated with this exothermic reaction is noteworthy. The surprisingly large internal energies that can be deposited in singly charged ions formed by charge exchange of doubly charged ions suggests a new route to the problem of activating ions, a problem that is currently a key issue [42] in applications of mass spectrometry to larger molecules. 
Knowledge of internal energy distributions is a significant aid in rationalizing and predicting the behavior of singly charged ions in the mass spectrometer [4]. The present data are potentially as valuable for ions generated in charge permutation reactions, which are of growing importance [43] in mass spectrometry. The information on the relative degrees of activation associated with EI and charge stripping may guide the choice of technique in particular circumstances.

\section{Supplementary Material}

Supplementary material for this article is available in photocopy form from the office of the Editor-in-Chief (see inside front of journal for address). Requests must include complete title of article, names of authors, issue date, and page numbers. The supplementary material consists of the illustrations listed below.

Figure S1. Electron impact mass spectrum $(70 \mathrm{eV})$ of $\mathrm{W}(\mathrm{CO})_{6}$. showing singly charged ions.

Figure S2. Electron impact mass spectrum $(70 \mathrm{eV})$ of $W(\mathrm{CO})_{6}$, showing doubly charged ions.

Figure S3. Dissociative charge stripping of $W(\mathrm{CO})_{6}{ }^{+\cdot}$ in $7.8-\mathrm{keV}$ collisions with molecular oxygen; $10 \%$ beam attenuation.

Figure S4. CAD product ion spectrum of $W(\mathrm{CO})_{6}{ }^{+}$in $7.8-\mathrm{keV}$ collisions with molecular oxygen; $10 \%$ beam attenuation.

Figure S5. CAD product ion spectrum of $\mathrm{W}(\mathrm{CO})_{6}{ }^{2+}$ in $7.8-\mathrm{keV}$ collisions with molecular oxygen; $10 \%$ beam attenuation.

Figure S6. Internal energy distribution in doubly charged $W(\mathrm{CO})_{6}{ }^{2+}$ ions generated by charge stripping of $W(\mathrm{CO})_{6}{ }^{+}$in $7.8-\mathrm{keV}$ collisions with molecular oxygen. Target pressure corresponds to $5 \%$ attenuation of the $W(\mathrm{CO})_{6}{ }^{+}$beam.

Figure 57. Internal energy distribution in doubly charged $\mathrm{W}(\mathrm{CO})_{6}{ }^{2+}$ ions generated by charge stripping of $W(\mathrm{CO})_{6}{ }^{+}$in 7.8-keV collisions with molecular oxygen. Target pressure corresponds to $50 \%$ attenuation of the $\mathrm{W}(\mathrm{CO})_{6}{ }^{+}$beam.

Figure 58. Internal energy distribution in $\mathrm{W}(\mathrm{CO})_{6}{ }^{+\cdot}$ generated by electron impact at $25 \mathrm{eV}$.

Figure S9. Internal energy distribution in $\mathrm{W}(\mathrm{CO})_{6}{ }^{+\cdot}$ generated by electron impacl at $15 \mathrm{eV}$.

Figure S10. Internal energy distribution in $\mathrm{W}(\mathrm{CO})_{6}+\cdot$ upon $\mathrm{CA}$ at $7.8 \mathrm{keV}$ with molecular oxygen. Target pressure corresponds to $10 \%$ attenuation of the projectile beam intensity.

Figure S11. Internal energy distribution in $\mathrm{W}(\mathrm{CO})_{5}{ }^{+}$upon $\mathrm{CA}$ at $7.8 \mathrm{keV}$ with molecular oxygen. Target pressure corresponds to $50 \%$ attenuation of the projectile beam intensity.

Figure S12. Approximate internal energy distribution in $\mathrm{W}(\mathrm{CO})_{3}{ }^{+}$generated by charge exchange of $\mathrm{W}(\mathrm{CO})_{3}{ }^{2+}$ with molecular oxygen. Target pressure corresponds to $50 \%$ attenuation.

\section{Acknowledgment}

Financial support by the United States-Yugoslavia Joint Fund for Scientific and Technological Cooperation and by the National Science Foundation (CHE 87-21768) is gratefully acknowledged.

\section{References}

1. (a) Cooks, R. G., Ed. Collision Speclroscopy; Plenum: New York, 1978. (b) Wesdemiotis, C.; McLafferty, F. W. Chem. Rev. 1987, 87, 485. (c) Holmes, J. L. Adv. Mass Spectrom. 1989 11A, 53. (d) Terlouw, J. K.; Schwarz, H. Angew. Chem. Int. Ed. Engl. 1987, 26, 805. (e) Neumann, G. M.; Derrick, P. J. Org. Mass Spectram. 1984, 19, 165. (f) Berkowitz, J; Groeneveld, K.-O., Eds. Molecular Ions, Plenum: New York, 1983. (g) Boers, A, L, Nucl. Instrum. Methods 1984, B4, 98. (h) Hemberger, P. H.; Laramee, J. A.; Hubik, A. R.; Cooks, R. G. J. Phys. Chem. 1981, 85, 233.

2. Cooks, R. G.; Howe, I.; Williams, D. H. Org. Mass Spectrom. 1969, 2, 137. (b) McLafferty, F. W.; Bente, P. F. III; Kornfeld, R.; Tsai, S.-C.; Howe, I. J. Am. Chern. Soc. 1973, 95, 2120. (c) MrAdon, D. J.; Bente, P. F. III; Gross, M. I.; McLafferty, F. W. Org. Mass Spectrom. 1974, 9, 525. (d) Das, P. R.; Nishimura, P.; Meisels, G. G. J. Phys. Chem. 1985, 89 , 2808. (e) Nacson, S.; Harrison, A. G. Int. J. Mass Spectrom. Ion Processes 1985, 63, 325. (f) Kemper, P. R.; Bowers, M. T. I. Phys. Chem. 1986, 90, 477. (g) Shukla, A. K.; Anderson, S. G.; Howard, S. L.; Sohlberg, K. W.; Futrell, J. H. Int. J. Mass Spectrom. Ion Processes 1988, 86, 61.

3. (a) Long, M. W.; Yates, B. F.; Nobes, R. H.; Radom, L. J. Am. Chem. Soc. 1987, 109, 181. (b) Jonathan, P.; Brenton, A. G.; Boyd, R. K. Int. J. Mass Spectrom. Ion Processes 1987, 76, 319. (c) Burdick, G. W.; Appling, J. R.; Moran, T. F. J. Phys. 1986, B19, 629. (d) Koch, W.; Maquin, F.; Stahl, D.; Schwarz, H. Chimia 1985, 39, 376. (e) Mazumdar, S.; Marathe, V. R.; Kumar, S. V. K.; Mathur, D. Int. J. Mass Spectrom. Ion Processes 1988, 86, 351. (f) Mathur, D.; Kingston, R. G.; Harris, F. M.; Beynon, J. H. I. Phys 1986, B19, L575. (g) Ast, T. Adv. Mass Spectrom. 1980, 8A, 555. (h) Wong, M. W.; Radom, L. Int. J. Mass Spectrom. Ion Processes 1988, 86, 319.

4. (a) Kenttämaa, H. 1.; Cooks, R. G. Int. J. Mass Spectrom. Ion Processes 1984, 64, 79. (b) Wysocki, V. H.; Kenttämaa, H. I.; Cooks, R. G. Int. J. Mass Spectrom. Ion Processes 1987, 75, 181.

5. (a) Wysocki, V. H.; Kenttämaa, H. I.; Cooks, R. G. Adv. Mass Spectrom. 1986, 9, 1109. (b) Kenttämaa, H. I. Org. Mass Spectrom. 1985, 20, 703. (c) Vincenti, M.; I lorning, S. R.; Cooks, R. G. Org. Mass Spectrom. 1988, 23, 585. (d) DeKrey, M. J.; Kenttämaa, H. I.; Wysocki, V. H.; Cooks, R. G. Org. Mass Spectrom, 1986, 21, 193.

6. (a) Cooks, R. G.; Beynon, J. H.; Ast, T. J. Am. Chem. Soc. 1972, 94, 1004. (b) Proctor, C. J.; Porter, C. J.; Ast, T.; Bolton, P. D.; Beynon, J. H. Org. Mass Spectrom. 1981, 16, 454. (c) Drewelio, I.; Schwarz, H. Int. J. Mass Spectrom. Ion Processes 1989, 87, 135.

7. (a) Cooks, R. G.; Beynon, J. H.; Litton, J. F. Org. Mass Spectrom. 1975, 10, 503. (b) Maquestiau, A.; van Haverbeke, Y.; Flammang, R.; Menu, A.; Wentrup, C. Org. Mass. Spectrom. 1978, 13, 518. (c) Holmes, J. L.; Terlouw, J. K.; Burgers, P. C.; Rye, R. T. B. Org. Mass Spectrom. 1980, 15, 149.

8. (a) Kingston, E. E.; Beynon, J. H.; Ast, T.; Flammang, R.; Maquestiau, A. Org. Mass Spectrom. 1985, 20, 546. (b) Kemp, D. L.; Beynon, J. H.; Cooks. R. G. Org. Mass Spectrom. 1976, 11, 857, (c) Ast, T.; Kraly, B.; Kramer, V.; Zigon, D. Int. 1. Mass Spectrom. Ion Processes 1988, 86, 329. (d) Jonathan, P.; Brenton, A. G.; Beynon, J. H. Org. Mass Spectrom. 1988, 23, 114. (e) Kemp, K. L.; Cooks, R. G. Collision Spectroscopy; Cooks, R. G., Ed. Plenum: New York, 1978; Ch. 5. 
9. (a) Cooks, R. G.; Ast, T.; Beynon, J. H. Int. J. Mass Spectrom. Ion Phys. 1973, 11, 490. (b) Stahl, D.; Maquin, F. Chem. Phys. Lett. 1984, 108, 613. (c) Ast, T, Adv. Mass Spectrom. 1985, 9, 471. (d) Sheil, M. M.; Derrick, P. J. Org. Mass Spectrom. 1988, 23, 429. (e) Bricker, D. L.; Russell, D. H. J. Am. Chem. Soc. 1986, 108, 6174 .

10. (a) Levsen, K. Fundamental Principles of Organic Mass Spectrometry; Verlag Chemie: New York, 1978; pp 12-17. (b) McLafferty, F. W.; Wachs, T.; Lifshitz, C.; Innorta, G.; Irving, P. J. Am. Chem. Soc. 1970, 92, 6867.

11. Vèkey, K.; Brenton, A. G.; Beynon, J. H. Int. J. Mass Spectrom. Ion Processes 1986, 70, 277.

12. (a) Litzow, M. R.; Spalding, T. R. Mass Spectrometry of Inorganic and Organometallic Compounds; Elsevier: Amsterdam, 1973; pp 475-490. (b) Kenttämaa, H. I.; Cooks, R. G. I. Am. Chem. Soc. 1985, 107, 1881.

13. Wysocki, V. H.; Kenttämaa, H. I.; Cooks, R. G. J. Phys. Chem. 1988, 92, 6465.

14. Vršçaj, V.; Kramer, V.; Medved, M.; Kralj, B. Int. J. Mass Spectrom. Ion Phys. 1980, 33, 409.

15. Cooks, R. G.; Beynon, J. H.; Caprioli, R. M.; Lester, G. R. Metustable Ions; Elsevier: Amsterdam, 1973.

16. (a) Winters, R. E; Kiser, R. W. Inorg. Chem. 1965, 4, 157. (b) Junk, G. A.; Svec, H. Z. Naturforsch. B 1968, 23, 1. (c) Foffani, A.; Pignataro, S.; Cantone, B.; Grasso, F. Z. Phys. Chem. 1965, 45, 79. (d) Bidinosti, D. R.; McIntyre, N. S. Can. J. Chem. 1967, 45, 641.

17. Russell, D. H.; Bricker, D. L. Anal. Chim. Acta 1985, 178, 117.

18. (a) Pan, Y. H.; Ridge, D. P. J. Phys. Chem. 1989, 93, 3375. (b) Georgiadis, R.; Armentrout, P. B. Int. J. Mass Spectrom. Ion Processes 1989, 91, 123 .

19. Turner, D. W.; Baker, C.; Baker, A. D.; Brundle, C. R. Molecular Photoelectron Spectroscopy; Wiley-Interscience: New York, 1970.

20. (a) Vincenti, M.; Horning, S. R.; Cooks, R. G. Adv. Mass Spectrom. 1989, 11A, 788. (b) van der Zande, W. J.; deBruijn, D. P.; Los, J.; Kistemaker, P. G.; McLuckey, S. A. Int. J. Mass Spectrom. Ion Processes 1985, 67, 161.

21. Larameé, J. A. Ph.D. Thesis, Purdue University, 1980; p 244.

22. Ast, T.; Beynon, J. H.; Cooks, R, G. J. Am. Chem. Soc. 1972, 94, 6611 .

23. (a) Kim, M. S.; McLafferty, F. W. J. Am. Chem. Soc. 1978, 100, 3279. (b) Kim, M. S. Int. J. Mass Spectrom. Ion Processes 1983, 50, 189. (c) Lee, S. H.; Kim, M. S.; Beynon, J. H. Int. J. Mass Spectrom. Ion Processes 1987, 75, 83.

24. (a) Bowie, J. H. Acc. Chem. Res. 1980, 13, 76. (b) Levsen, K.; Schwarz, H. Mass Spectrom. Kev. 1984, 2, 77. (c) Holmes, J. L. Org. Mass Spectrom. 1985, 20. 169. (d) Bursey, M. M.; Harvan, D. J.; Parker, C. E.; Pederson, L. G.; Hass, J. R. J. Am. Chem. Soc. 1979, 101, 5489. (e) Burinsky, D. J.; Cooks, R. G. Org. Mass Spectrom. 1983, 18, 410 .
25. Engelking, P. C.; Lineburger, W. C. J. Am. Chem. Soc. 1979, 101, 5569.

26. (a) Young, A. B.; Harrison, A. Org. Mass Spectrom. 1987, 22, 622. (b) Tumas, W.; Salomen, K. E.; Brauman, J. I. J. Am. Chem. Soc. 1986, 108, 2541.

27. Vèkey, K.; Brenton, A. G. Rapid Commun. Mass Spectrom. $1988,2,156$.

28. (a) Hasted, J. J. Appl. Phys. 1959, 30, 25. (b) Massey, H. S. W.; Burhop. E. H. S. Electron and Ionic Impact Phenomena; Oxford Univ.: London, 1956; pp 441, 515. (c) Cooks, R. G. Collision Spectroscopy; Plenum: New York, 1978; p 383.

29. Bearman, G. H.; Ranjbar, F.; Harris, H. H.; Leventral, J. J. Chem. Phys. Lett. 1976, 42, 335.

30. Beynon, J. H.; Cooks, R. G., J. Phys. E 1974, 7, 10.

31. (a) Boyd, R, K, Presented at the 11th International Mass Spectrometry Conference, Bordeaux, France, August 29-September 2, 1988; paper THA26. (b) Curtis, J. M.; Boyd, R. K. J. Chem. Phys. 1984, 80, 1150.

32. Vékey, K.; Brenton, A. G.; Beynon, J. H. Int. J. Mass Spectrom. Ion Processes 1986, 70, 277.

33. Vékey, K.; Brenton, A. G.; Beynon, J. H. Int. J. Mass Spectrom. Ion Processes 1989, 87, 121.

34. Harrison, A. G. Chemtical Ionization Mass Spectrometry; CRC: Boca Raton, FL, 1983.

35. Johnson, R. E.; Boring, J. W. In Collision Spectroscopy; Cooks, R. G., Ed.; Plenum: New York, 1978; Chapter 2.

36. (a) Stueckleberg, E. C. G. Helv. Phys. Acta 1932, 5, 369, (b) Landau, L. Phys. Z. U.S.S.R. 1932, 1, 88. (c) Zener, C. Proc. Roy. Soc. (London) 1932, A137, 696.

37. Bierly, J. H.; Herschbach, D. R. J. Chem. Phys. 1966, 44, 1690.

38. (a) Ast, T.; Beynon, J. H.; Cooks, R. G. Org. Mass Spectrom. 1972, 6, 749. (b) Sakuri, H.; Tatematsu, A.; Nakata, H. Bull. Chem. Soc. Japan 1974, 47, 2731. (c) Sim, P. J ; Jamieson, W. D; Boyd, R. K. Org. Mass Spectrom. 1989, 24, 327.

39. Russell, D. H., Proceedings 37th ASMS Conference on Mass Spectrometry and Allied Topics, Miami Beach, FL, 1989; p 403.

40. Horning, S. R.; Vincenti, M.; Cooks, R. G. J. Am. Chem. Soc., in press.

41. (a) Curtis, J. M.; Vékey, K.; Brenton, A. G.; Beynon, J. H. Org. Mass Spectrom. 1987, 22, 289, (b) Curtis, J. M.; Brenton, A. G.; Beynon, J. H.; Boyd, R. K. Org. Mass Spectrom. 1987, 22, 779 .

42. (a) Sheil, M. M.; Derrick, P. J. In Mass Spectrometry in Biomedical Research; Gaskell, S. J., Ed; Wiley: Chichester, 1986; p 251. (b) Hunt, D. F.; Yates, J. R.; Shabanowitz, J; Winston, S.; Hauer, C. R. Proc. Natl. Acad. Sci. U.S.A. 1986, 83, 6233.

43. (a) Beynon, J. H.; Boyd, K. K.; Brenton, A. G. Ado. Mass Spectrom. 1985, 10, 437. (b) Hunt, D. F.; Zhu, Nia-Zhou; Shabanowitz, J. Rapid Commun. Mass Spectrom. 1989, 3, 122. (c) Mabud, M. A.; DeKrey, M. J.; Cooks, R. G.; $\Lambda$ st, T. Int. J. Mass Spectrom. Ion Processes 1986, 69, 277. 